\title{
Nevada Underserved Science Education Program (NUSEP) Summary
}

The Nevada Underserved Science Education Program provided training for 43 Nevada science teachers over a two-week period from July 28- August 8 in the summer of 2003. Participants in this program were trained in materials developed by NASA, Space Education Initiatives, and Space Explorers Incorporated. A summary of these materials is attached along with the teacher evaluation of these materials conducted at the conclusion of the workshop.

The training was taught in a hands-on, experiential manner that allowed participants to take on the roll of the classroom student. This approach allowed teachers to learn the information being taught by the activities through the unique perspective of students. The following descriptions of each activity give a brief overview of the major objectives and concepts covered by the individual units.

\section{Unit Summaries}

\section{Mars Exploration}

This one-hour lecture and slide show discusses current Mars exploration activity including plans for the near future and opportunities for educator involvement.

\section{Classroom Comet}

Students learn the basic components of a comet and demonstrate how the comet's head and tail form by building one.

\section{Air Powered Rockets}

Building and flying rockets is an exciting and educational way to introduce students of any age to aerospace education, this lesson provides suggested guidelines for students to produce cheap, safe, and reusable paper rockets that can be used to demonstrate both physical science principles, as well as mathematical concepts.

\section{GPS Training}

This workshop includes basic map and GPS skills, along with a presentation describing how the Global Positioning System functions. Upon completion of this portion of the training teachers are eligible to receive 15 handheld receivers for use in their classroom each year.

\section{GEODe Program}

An interactive CD-Rom program which covers the basics of geology from mineral identification through geological evolution. 


\section{Thermal Protection System}

When spacecraft travel at high speeds through the Earth's atmosphere they generate high temperatures on their surfaces due to frictional heating. Space vehicles must have thermal protection systems to protect them from this heat. In this challenge, students learn about the process of how NASA engineers design lightweight but effective reusable thermal protection systems. Working in two-person teams they design, build, and test a thermal protection system of their own design. They use simple materials such as wood dowels, aluminum foil and screening to build a model that can withstand the heat of a propane torch.

\section{Spacecraft Structures}

The structural elements that hold together an aerospace vehicle must be strong and as light as possible in order to minimize the fuel needed to get to orbit. NASA engineers continually strive to develop new materials and methods in structural design. In this challenge, students undertake the problem of designing a strong but lightweight thrust structure that can withstand the launch of a bottle rocket by means of a wooden lever. Using simple materials such as craft sticks, cardboard, and glue students strive to make their structure lighter while maintaining its' strength.

\section{Radial Solar System Model}

Construct a movable model of the solar system that allows students to track the current location of planets in the solar system.

Whispers in Space

The NASA Deep Space Network - or DSN - is an international network of antennas that supports interplanetary spacecraft missions and radio and radar astronomy observations for the exploration of the solar system and the universe. This activity uses umbrellas and stopwatches to show how a parabolic dish transmits and receives very weak signals over long distances.

Marslink Simulation

Through Marslink ${ }^{\circledR}$ students have the opportunity to become actively involved in the Mars Odyssey mission. Students learn about the Martian environment and make discoveries right along with mission science teams as they seek answers to questions about the Red Planet.

Space Education Initiatives Website

Review of materials contained on the website including online interactive simulations for the classroom. Gravity, Planet Comparison, and Moon Phases are fully functional learning guides for students.

Grapple the Satellite and Orbital Laboratory

This module allows students to participate in research being conducted on the International Space Station. They learn how living organisms function differently in a microgravity environment through botanical and biological experimentation and inquiry. 


\section{Can A Fish Swim in Space?}

Fish in Space is a life in space science module suited for the middle school classroom. It asks students to consider the requirements for taking a living system into the space environment. While it teaches specific life science concepts, especially as they relate to organisms, it also teaches many science process skills such as,

- $\quad$ The ability to inquire.

- Knowing and understanding scientific facts, concepts, principles, laws, and theories.

- The ability to reason scientifically.

- The ability to communicate effectively about science.

The module consists of 12 ficticious "Memos" from a NASA researcher asking for the students help in planning and developing an experiment to take 4 Japanese killifish into space for 16 days.

\section{Additional Workshops}

One Nevada teacher participated in the Marshall Space Flight Center Workshop in February 2004. The workshop included 2 full days at Marshall Space Flight Center and 1 day at the U.S. Space and Rocket Center. Educators experienced first-hand the excitement and challenges of NASA's space program. The goal of the workshop was three-fold: 1) to provide educators with the background and experience that will add to their knowledge base as an educator, 2) to make connections between space science and school curriculum that will allow educators to enhance their instruction, and 3) to create a network of educators around the nation to act as space science resources for the teaching community.

Two Nevada teachers participated in the NASA JPL/Dryden/DSN workshop. The workshop included one full day at the Jet Propulsion Laboratory, one full day at the Deep Space Network's Goldstone Facility, one full day at NASA Dryden, and one day of speakers and presentations in Pasadena, CA. This workshop experience included the "lifecycle" tour of JPL that illustrates the entire process of designing, building and operating a robotic mission for Solar System exploration. The tour included visits to the Mars In-Situ testing facility, environmental testing facility, clean room, Team X mission design facility, Deep Space Network operations gallery, and the Space Flight Operations building. The tour of the Goldstone Facility illustrated how engineers communicate with spacecraft throughout the Solar System using giant radio telescopes. 